\title{
A contribuição do trabalho odontoló
na resolução de problemas de saúde da população: a concepção de alunos de Odontologia
}

| 'Calvino Reibnitz Júnior, ${ }^{2} J$ ão Carlos Caetano, ${ }^{3}$ Marta Lenise do Prado |

Resumo: O presente estudo tem por objetivo analisar e discutir a compreensão de alunos dos sete cursos de Odontologia no Estado de Santa Catarina, quanto à contribuição do trabalho odontológico na resolução dos problemas de saúde da população. A estratégia metodológica utilizada foi a pesquisa qualitativa baseada na técnica do discurso do sujeito coletivo (DSC), através de 35 entrevistas. Os resultados possibilitaram a elaboração de sete DSCs, ficando evidente nos mesmos que a contribuição do trabalho odontológico para esses alunos passa pela disseminação do conhecimento em saúde bucal do dentista à população, como forma de esta se prevenir; que a assistência clínica requer a boa formação técnica do dentista, com a utilização de bons materiais, instrumentais e equipamentos, aliada ao respeito dos preceitos éticos e da satisfação com o trabalho desenvolvido; que a resolução de problemas dentários é a forma de promover a autoestima das pessoas, fazendo sua inclusão social; que a Odontologia não se limita a suas questôes específicas, devendo também considerar aspectos de outras profissōes; que há necessidade de se melhorar a infraestrutura e o acesso aos serviços públicos de saúde. Os resultados apontam para a necessidade desses sete cursos de Odontologia realizarem, com a comunidade acadêmica, discussōes visando à reflexão crítica do campo conceitual da saúde bucal.

> Palavras-chave: saúde bucal; trabalho odontológico; ética profissional; educação superior.

\author{
${ }^{1}$ Professor assistente no \\ Departamento de Odontologia, \\ Curso de Odontologia da UFSC; \\ Mestre em Saúde Pública pela \\ UFSC e doutorando em \\ Odontologia em Saúde Coletiva \\ pela UFSC. Endereço eletrônico: \\ calvinoodonto@ccs.ufsc.br. \\ 2 Professor titular no \\ Departamento de Saúde \\ Pública, Curso de Odontologia \\ da UFSC e Curso de Pós- \\ graduação em Odontologia em \\ Saúde Coletiva da UFSC; \\ Doutor em Odontologia Social \\ pela UFF. \\ ${ }^{3}$ Professora associada no \\ Departamento de Enfermagem \\ e do Programa de Pós- \\ graduação em Enfermagem; \\ Doutora em Filosofia da \\ Enfermagem pela UFSC.
}

Recebido em: 20/08/2008. Aprovado em: 16/09/2008 


\section{Introdução}

O avanço da odontologia nas últimas três décadas é inquestionável, especialmente devido à produção de materiais restauradores mais resistentes e com padrōes estéticos que satisfazem plenamente os consumidores, assim como a incorporação de aparelhos de alto requinte e de técnicas cirúrgicas menos invasivas e mais resolutivas. Todavia, na prática o que se verifica é que a maioria da população brasileira não tem acesso a estas tecnologias em virtude de seu alto custo. Isto se traduz numa grande preocupação, pois, aliado a esse fato, a rede pública não se encontra capacitada para prestar assistência odontológica à alta demanda existente.

Agravando mais este quadro, o modelo de prática odontológica em nosso país ainda se encontra dentro do paradigma biomédico, caracterizado por uma prática centrada na assistência odontológica, com foco no tratamento das sequelas das doenças bucais, realizada pelo dentista de forma individualizada (NARVAI, 1994). O mais preocupante de tudo é que este modelo tem influenciando de forma decisiva as ações desenvolvidas no setor público.

Os dentistas, de maneira geral, entendem que o trabalho clínico é suficiente para solucionar os problemas de saúde da população. Esta forma de pensar é em parte consequência da formação, já que a predominância nos currículos dos cursos de graduação é de objetivos de domínio cognitivo (teoria) e psicomotor (prática), com o dispêndio da maior parte da carga horária da matriz curricular voltada às abordagens individuais em questôes clínicas e preventivas das doenças bucais. Outro fator que contribui para este pensamento é o fato de a maioria trabalhar sozinha ou com uma auxiliar de consultório dentário (ACD) em consultório na rede privada, de forma individualizada, executando procedimentos clínicos cirúrgico-restauradores.

Uma formação assim orientada pouco tem contribuído para a melhoria do quadro de saúde bucal da população brasileira. Para isso, se faz necessário que o processo ensino-aprendizagem transponha a formação de profissionais qualificados científica e tecnicamente, preocupando-se também em formar cidadãos com visão crítica suficiente para atuar na melhoria dos níveis de saúde da coletividade (REIBNITZ; PRADO, 2003). Também é necessário que a formação ultrapasse as questôes teóricas e técnicas, possibilitando aos alunos novos espaços de aprendizagem onde possam vivenciar a realidade de vida das pessoas e refletir criticamente com as mesmas sobre as verdadeiras razões do processo saúde-doença, capacitando-as na busca da conquista dos direitos de cidadania. 
Nesse contexto, a formação dos novos profissionais precisa favorecer uma compreensão ampliada do processo saúde-doença e do papel do dentista no campo da saúde. Assim, o objetivo deste trabalho foi analisar a compreensão dos alunos dos cursos de Odontologia de Santa Catarina, Brasil, quanto à contribuição do trabalho odontológico na resolução dos problemas de saúde da população. ${ }^{1}$

\section{Percurso metodológico}

Trata-se de uma pesquisa realizada no ano de 2007, abrangendo alunos dos sete cursos de Odontologia do Estado de Santa Catarina (FURB, UFSC, UNISUL, UNIVILLE, UNIVALI, UNOESC e UNIPLAC). A estratégia metodológica utilizada foi a de pesquisa qualitativa baseada na técnica do discurso do sujeito coletivo (DSC), conforme estabelecem Lefevre e Lefevre (2003), sedimentada na teoria das Representações Sociais. O DSC consiste na forma de representar o pensamento da coletividade, agregando num discurso-síntese os conteúdos discursivos de sentido semelhante, emitidos por pessoas distintas.

De cada uma das instituiçôes foram entrevistados cinco alunos formandos, selecionados de forma aleatória através de sorteio numérico, utilizando-se como referência a lista de presença. $\mathrm{O}$ tamanho final da população do estudo foi estabelecido pela amostragem por saturação, quando a inserção de novos integrantes às informações já coletadas pouco acrescentaram ao material já obtido, deixando de contribuir de modo significativo para o aperfeiçoamento da reflexão teórica fundamentada nos dados já analisados (FONTANELLA; RICAS; TURATO, 2008).

As entrevistas foram realizadas por meio de agendamento prévio, em local reservado com garantia de privacidade. As entrevistas foram gravadas e seguiram um roteiro contendo seis perguntas, dentre as quais: "como o trabalho odontológico pode contribuir para a resolução dos problemas de saúde da população?”. A pesquisa cumpriu todas as exigências da Resolução no 196/96 do Conselho Nacional de Saúde, assim como o projeto de pesquisa se submeteu a análise do Comitê de Ética em Pesquisa com Seres Humanos da UFSC, recebendo a aprovação conforme parecer consubstanciado - projeto n. ${ }^{\circ} 301 / 2006$.

Os dados foram organizados de acordo com o proposto pelo método do DSC, em forma de um painel de discursos, do qual foram extraídas as figuras metodológicas como as expressōes-chave (ECH), a idéia central (IC) e o DSC propriamente dito. O resultado final refletiu o pensamento de cada um e o conjunto de depoimentos 
coletados sobre o tema. A análise dos depoimentos possibilitou a elaboração de sete DSCs, agrupados neste texto em quatro temas para facilitar sua organização e compreensão. Os resultados abordam o enfoque principal de cada discurso.

\section{Resultados e discussão}

Os discursos dos alunos de Odontologia dos cursos de graduação das instituiçães de ensino de Santa Catarina demonstram sua compreensão sobre como o trabalho odontológico pode contribuir na resolução dos problemas de saúde da população e estão expressos a seguir.

\section{0. tema: Por meio da educação e da prevenção}

Neste tema encontram-se os DSC1 e DSC2, sendo que o DSC1 está incluído na IC "principalmente fazendo mais prevenção com a educação das pessoas", tendo a seguinte redação:

Como as pessoas estão doentes, com infecção na boca, com perda dos dentes por várias causas, é preciso fazer prevenção. Trabalhar a conscientização das pessoas em relação aos problemas de saúde, motivá-las e tentar convencê-las a mudarem hábitos errados. Mostrar como se faz a prevenção, dar instruçôes de como cuidar realmente da sua saúde geral e saúde oral, ensinar sobre escovação, como usar o fio dental, como manter os dentes na boca, como usar o flúor e como se alimentar, e a importância de procurar o dentista periodicamente. Tudo isto para capacitálas ao autocontrole de sua saúde. O principal é convencer a população do que é bom para ela, fazendo-a aceitar a mudança para esse novo modelo de saúde e partir para a prevenção.

O DSC2 faz parte da IC "possibilitando à população conhecimento em saúde bucal como forma de se prevenir”. O teor deste discurso está assim sintetizado:

Só restaurar não vai resolver o problema de todo mundo. A Odontologia precisa se voltar à prevenção. $\mathrm{O}$ povo precisa de educação para se prevenir. As pessoas precisam ter consciência sobre todos os fatores que geram doenças bucais para poderem controlá-los e conseguir a prevenção. O dentista deve mostrar que a prevenção é mais importante do que o tratamento odontológico.

O que fica evidente em ambos os discursos é que a principal contribuição do trabalho odontológico é a disseminação, para a população, do conhecimento que o dentista traz consigo, uma vez que a ênfase se encontra quase exclusivamente 
voltada à aquisição, por parte da população, de conhecimento sobre a saúde bucal. Portanto, no entender dos alunos, o saber a ser adquirido pela população tem relação com o modo como ela vai se conscientizar de seus problemas de saúde, e desta maneira tomar atitudes preventivas com relação às doenças. No entanto, os alunos não consideraram os determinantes sociais do processo saúde-doença, a vontade das pessoas em querer promover mudanças e a posse de condições necessárias para fazê-lo. Sabe-se que entre as funçōes dos dentistas em seu trabalho com a população destacam-se a educação em saúde bucal e as atividades clínicas, mas a melhora na saúde da população não pode ficar restrita a estas atividades, uma vez que as mesmas não são suficientes para manter níveis desejáveis de saúde.

Outra questão não apontada pelos alunos é a importância do planejamento e da programação em ações de saúde bucal, assim como da coordenação, supervisão, execução e avaliação dessas ações. Possivelmente a desconsideração destas funções seja fruto da formação acadêmica que se encontra voltada para um currículo cujo foco é a atividade clínica de forma individualizada.

Para Moysés e Watt (2000), a educação dirigida aos indivíduos tem o objetivo de proporcionar o conhecimento, habilidades e convicçôes necessárias para adoção de estilo de vida mais saudável. No entanto, a educação não deve ter a intenção de persuasão para a mudança em determinada direção, mas proporcionar possibilidades de escolha, tornando as pessoas habilitadas a agir de acordo com o caminho que considerarem mais apropriado.

Os profissionais de saúde, apesar de terem o conhecimento técnico, não podem usá-lo como forma de subjugar as pessoas, pois o conhecimento a elas colocado dependerá em muito do seu nível de aceitação. Se as mesmas entenderem que do jeito em que se encontram já possuem qualidade de vida e boa situação de saúde, não será enchendo-as de recomendações que irão mudar seu comportamento. A autonomia desejada às pessoas não pode ser realizada de forma outorgada; ela precisa ser conquistada pelos próprios sujeitos (SEGRE; FERRAZ, 1997).

Não se pode negar que as pessoas têm capacidade para, de alguma forma, controlar sua saúde. No entanto, para mudar comportamentos considerados inapropriados, não basta só fornecer as razões para tal, é preciso que as pessoas tenham a seu dispor recursos e meios para fazê-los. Existe uma diferença entre possuir conhecimento e habilidades e a capacidade de usá-los de forma efetiva e consistente diante de condiçôes adversas (SOUZA; SILVA; GALVÃO, 2002). 
É importante deixar claro que o conhecimento pode contribuir para a conscientização das pessoas, mas não basta apenas conscientizar, é preciso agir. Apesar de as necessidades de saúde sentidas pela população precisarem ser solucionadas, a saúde bucal não pode se limitar às questões práticas da profissão. No trabalho em saúde, os determinantes sociais, econômicos, políticos e culturais do processo saúde-doença precisam ser levados em consideração. Os dentistas não podem limitar seu papel apenas à execução de suas ações no trabalho diário com seus pacientes. Devem também considerar toda a sociedade, participando ativamente, junto ao poder público, na exigência do estabelecimento de políticas públicas mais abrangentes e na reestruturação do sistema de saúde pública para atender efetivamente aos princípios doutrinários do SUS, como forma de proporcionar benefícios a todos.

\section{2o. tema: É preciso realizar tratamento}

Este tema inclui os DSC 3 e DSC4. O DSC3 se encontra inserido na IC "considerando a saúde de forma ampliada" e tem o seguinte conteúdo:

A Odontologia não é só olhar para a cárie e para os dentes, mas sim trabalhar na visão global do paciente, seja dentro da comunidade ou dentro do consultório, alertando sobre a obesidade, o diabetes e a hipertensão.

$\mathrm{Na}$ IC "profissional com bom domínio teórico-prático e boas condições de trabalho" se encontra no seguinte discurso:

Para atender a clientela particular e da rede pública, o dentista precisa estar atualizado, ter domínio da teoria e da parte técnica. O conhecimento teórico é importante para fazer bom diagnóstico, planejamento e saber tratar, para ver o melhor modo de educar o paciente. É claro que para dar atendimento de qualidade, as questôes de tecnologia, de equipamento, de materiais e de instrumental também são muito importantes, aliadas a profissionais satisfeitos com seu trabalho e sua remuneração (DSC4).

Percebe-se inicialmente concordância entre os conteúdos dos dois discursos no que tange à necessidade de o dentista estar bem preparado para exercer sua profissão. A ênfase no domínio do conhecimento teórico e da habilidade para as questóes clínicas é bem visível. Trata-se de um profissional com capacidade cognitiva e técnica suficiente para fazer diagnósticos individuais e coletivos, identificar tipos de doença, realizar tratamento e educar pessoas. 
É inegável que a formação acadêmica deve capacitar o aluno para as especificidades da sua profissão, mas a conduta do mesmo no futuro dependerá em muito do enfoque que foi dado a sua formação - ou seja, se a visão foi puramente biológica, curativa, individual e focada na doença ou se foi a da complexidade do viver, do coletivo, da construção da cidadania, com o enfoque voltado à saúde. A solução dos problemas de saúde não se encontra unicamente na resolução dos problemas instalados; é preciso também problematizar junto às pessoas as reais razões para o estado das desigualdades socioeconômicas e do modo como as doenças afetam a maioria da população.

Para os alunos, o dentista na sua prática tem que levar em conta a saúde geral das pessoas, podendo-se entender que o trabalho odontológico não pode se limitar às questões próprias da odontologia, devendo considerar especificidades de outras profissões, o que se expressa no discurso a seguir:

[...] o dentista em seu trabalho deve abranger outras áreas ligadas à saúde, reforçando o que outros profissionais falam, ajudando a melhorar a saúde, descobrindo doenças, encaminhando as pessoas para posto de saúde ou médico particular. Embora o dentista vá cuidar da boca, dos dentes, não pode trabalhar isolado dos outros profissionais da saúde. (DSC3).

Esta colocação é positiva, uma vez que evidencia que os problemas bucais podem contribuir para o agravamento de problemas de saúde geral e vice-versa. Outro fato a ser destacado, embora de forma incipiente, é a idéia de interdisciplinaridade, o que pode ser o reflexo de uma nova formação dos futuros dentistas, haja vista os processos de reestruturação curricular em andamento nos diferentes cursos. Diferentemente do trabalho multidisciplinar que fragmenta o organismo do indivíduo, cabendo a cada profissional fazer apenas a parte específica da profissão, a interdisciplinaridade corresponde à nova consciência da realidade, ao novo modo de pensar, que resulta no ato de troca, de reciprocidade e integração entre áreas com diferentes conhecimentos, visando tanto à produção de novos conhecimentos, como à resolução de problemas de modo global e abrangente (FAVARÃO; ARAÚJO, 2004). Para tanto, os profissionais deverão relacionar-se de forma horizontal, contribuindo com seus conhecimentos, habilidades e atitudes na busca do sucesso do tratamento.

A idéia de que a resolução de problemas dentários é também uma forma de promover a autoestima das pessoas podendo, portanto, fazer a sua inclusão social, aparece no DSC3: 
[...] analisar o paciente no todo, com exames complementares e radiográficos, saber de seus hábitos, da sua saúde geral e fazer a parte curativa para resolver os problemas de saúde, como na saúde bucal, que pode resolver problemas de estética dental, o que diminuirá constrangimentos, facilitará o relacionamento com os demais e para arranjar emprego, o que poderá transformar a vida social do indivíduo.

Esse trecho evidencia que é inegável que as necessidades de saúde bucal da população precisam ser solucionadas. $\mathrm{O}$ atendimento restaurador, ao promover um sorriso apresentável e o restabelecimento da função mastigatória, possivelmente naquele momento melhora a autoestima. O que precisa avançar no discurso dos alunos são as condições nas quais as pessoas vivem para manter o quadro de saúde que foi recomposto. A falta de boas condições acaba determinando às pessoas o retorno aos serviços de saúde para novos tratamentos, o que prejudica a autoestima.

Quanto à inclusão social, esta não se concretizará apenas pela resolução dos problemas de saúde bucal. Os problemas como a falta de boa moradia e de emprego que garanta o sustento da família dependem em muito do estabelecimento de políticas públicas adequadas e resolutivas. Portanto, a inclusão social não se concretiza apenas pela prestação de serviços de saúde, e só acontecerá quando houver uma distribuição de renda mais equitativa no país, possibilitando aos menos favorecidos sua inserção em todos os aspectos e dimensões da vida. Também passa pelo reconhecimento do cidadão como força produtiva no desenvolvimento do país.

Nesse sentido, acredita-se que a saúde deve ser considerada como um direito social, não vinculada apenas à possibilidade do poder de compra da assistência por parte do indivíduo, mas também à atividade obrigatória do Estado como prestador de serviços. Deve configurar-se como direito a não adoecer, impondo ao Estado atuar de forma antecipada aos problemas de saúde. O indivíduo, além do direito à cura e à prevenção de doenças, também tem direito a uma vida saudável, aos benefícios do desenvolvimento, às condições elementares como renda e recursos, e ao respeito próprio e a inclusão social (LUIZ, 2005).

Outro fato que precisa ficar evidente é que as desigualdades em saúde não se limitam à área de atuação do setor saúde, tanto no que diz respeito a sua abordagem conceitual quanto a identificação e desenvolvimento de intervençōes visando à solução de problemas. Para a diminuição ou limitação dos efeitos negativos à saúde, são exigidas políticas, programas e intervençôes com características multissetoriais (OPAS, 2004). 
Os alunos também fazem referência à qualidade do trabalho odontológico. Para eles:

[...] para dar atendimento de qualidade no trabalho odontológico, as questôes de tecnologia, de equipamento, de materiais e de instrumental também são muito importantes, aliadas a profissionais que estejam satisfeitos com seu trabalho e sua remuneração e que saibam trabalhar com a população. (DSC4).

Esta visão é positiva, uma vez que a prática clínica em saúde bucal, para ser efetiva, deve respeitar as técnicas específicas exigidas para cada tipo de procedimento, assim como usar materiais biocompatíveis e seguir as normas de biossegurança. A satisfação com a profissão, para ser obtida, necessita levar em conta vários aspectos, um dos quais é a remuneração, que deve ser a mais justa possível, possibilitando ao profissional condição dignas de sobrevivência. No setor público, o que se observa é uma disparidade nos valores salariais pagos aos dentistas. Cada município tem estabelecido seu valor e em sua maioria os valores pagos não permitem a dedicação exclusiva ao emprego. Outro fato agravante é a precarização nos contratos de trabalho, não possibilitando a estabilidade no emprego, gerando incerteza quanto ao futuro do profissional. Este fato pode até gerar um desestímulo, deixando o profissional de criar vínculo com a comunidade, o que o levará a um descompromisso com as pessoas a serem atendidas. $\mathrm{Na}$ rede privada tem ocorrido expansão do atendimento a pacientes com base em convênios ou seguro-saúde. De maneira geral, essas duas modalidades remuneram muito mal os procedimentos executados, o que acaba provocando insatisfação com a profissão. Tudo isto contribui para a prestação de serviços não-resolutivos e de qualidade duvidosa, gerando insatisfação na população atendida e descrédito no sistema de saúde.

A precarização nos contratos de trabalho de dentistas fica constatada no estudo de Nickel e Corrales (2006), feito com 777 equipes de saúde da família no Estado de Santa Catarina, entre os anos de 2002 a 2005. A maioria se caracterizou por prazo determinado e por salários abaixo da média nacional, portanto, não possibilitando satisfação com o trabalho. No entanto, embora muitas vezes as condições de trabalho e a remuneração sejam consideradas como ideais, a pressão pela produtividade, falta de autonomia técnica para a execução do trabalho, concorrência entre os profissionais e instabilidade no emprego podem causar ao profissional problemas psicológicos, físicos e emocionais. O ideal é que o profissional esteja amparado por leis trabalhistas 
e que possa efetivamente exercer seu direito de participar no planejamento, na organização e no método de produção de sua profissão.

Para Nicolielo e Bastos (2002), independentemente do setor onde o dentista estiver atuando, ele só se sentirá estimulado com a profissão se estiver satisfeito com seu trabalho. Uma profissão, em sua prática, não deve ser considerada somente como o resultado de aptidões e habilidades de quem as executa. Os fatores psicológicos e sociais produzem grande influência no comportamento do trabalhador no seu exercício profissional e condicionam sua compatibilização com seu trabalho. É esta compatibilização que leva à chamada satisfação profissional.

Para Freitas (2007), a prática odontológica atual tem colocado novos obstáculos aos dentistas, o que tem gerado insatisfação com a profissão. A carga horária de trabalho, a remuneração recebida, o ideal de serviço e o grau de autonomia para execução de suas atividades são fatores contributivos para a satisfação pessoal com a profissão. A experiência e o significado que cada profissional atribui a sua prática representam sua individualidade. $\mathrm{O}$ sentimento de desvalorização e desprestígio leva ao desencantamento com a profissão.

\section{0. tema: Gestão pública de melhor qualidade}

Neste tema estão incluídos os DSC5 e DSC6. O DSC5 faz parte da IC "melhorando a infraestrutura e o acesso aos serviços públicos de saúde e dirigindo ações aos mais necessitados", tendo o seguinte conteúdo:

Com relação à população em geral, pode-se contribuir com a rede pública, mas esta ainda tem muito que melhorar, principalmente no acesso da população carente ao dentista, apesar de os projetos do governo estarem no caminho certo. Os postos de saúde precisam ter melhores materiais, mais funcionários, mais dentistas, inserir o PSF que faz o reconhecimento da área em que atua, se encaixando dentro do contexto de vida das pessoas, conseguindo trabalhar direto na realidade. As açôes devem ser mais dirigidas para as populações carentes e para escolas públicas, para aqueles que têm menos acesso, com programas educativos. É preciso também dar mais acesso à parte emergencial, tratar os problemas prioritários das pessoas.

A IC "maior investimento público à saúde, tratamento integral, aumento da resolubilidade e enfoque em ações preventivas" inclui o DSC6, assim expresso:

Não vai ser a classe dos cirurgiōes-dentistas que vai poder arrumar. Falta investimento do governo para o setor público. O SUS na prática não acontece. Precisa melhorar para atender à população, com menos burocracia para os projetos acontecerem e 
também com investimentos por parte das prefeituras. A porta de entrada é a atenção básica, mas muitas pessoas precisam saber onde podem ser atendidas. Depois da entrada vem a longitudinalidade do tratamento, devem ter o direito de receber todo o tratamento que necessitam. Melhorar a resolubilidade que ainda é muito baixa, devido à má administração de recursos materiais e humanos, ao tipo de tratamento voltado mais às urgências ou mesmo pelas faltas dos pacientes às consultas agendadas. É necessário que os serviços de saúde tenham um atendimento mais abrangente. Focar mais na prevenção para sobrar menos problemas para serem tratados na clínica.

Analisando-se ambos os discursos, nota-se que o entendimento dos alunos é que o poder público não tem cumprido suas obrigações com relação à saúde da população, pois se enfatiza a necessidade de maior investimento no SUS para proporcionar mais acesso e melhores condiçôes de atendimento. Deve-se ainda proceder a ações de educação dirigida ao segmento da população mais carente.

Quanto às obrigações do governo em termos de saúde, a própria Constituição Federal prevê o funcionamento do SUS, com ações de promoção, proteção, assistência e reabilitação dirigidas a toda a população brasileira, respeitandose os princípios doutrinários da universalidade, equidade e integralidade, assim como as diretrizes organizacionais da descentralização, da hierarquização e da participação comunitária.

O entendimento de que as unidades básicas de saúde devem atender mais às pessoas carentes pode ser determinado pelo fato de esses alunos terem tido experiências em que o fluxo de demanda se caracterizava pelo segmento desta população, o que é perfeitamente esperado, uma vez que os problemas de saúde são mais abundantes nas pessoas com menos condições socioeconômicas, pois a saúde está fortemente relacionada às condiçōes de vida.

Quanto aos investimentos públicos, estes devem destinar-se, além da rede de prestação de serviços de saúde em todos os níveis de atenção, à área social onde se encontram muitos dos determinantes do processo saúde-doença. Convém ressaltar que a melhoria no funcionamento do SUS não depende exclusivamente da disponibilização de recursos financeiros. Fatores como a capacidade racional de gestão pública e o efetivo controle social são altamente decisivos para o estabelecimento das prioridades em saúde. O controle social, estabelecido na Constituição Federal, podese expressar sobretudo pelas Conferências de Saúde e pelos Conselhos de Saúde. Os Conselhos são os órgãos decisórios com a função de formular e deliberar sobre as 
políticas públicas, assim como fiscalizar a execução das ações dos administradores públicos relacionadas às políticas sociais (BRASIL, 2005).

Outro fato a ser destacado é que os discursos dos alunos deixam transparecer que o entendimento do SUS praticamente se limita às unidades básicas de saúde com a prestação de assistência, visando a resolver as patologias apresentadas pelos usuários. No entanto, as unidades de saúde não podem ser vistas apenas como o local de consultas, pois também fornecem medicamentos e realizam a prevenção de doenças através do programa de imunização. Além disso, a resolução de problemas de saúde pode não se esgotar no nível da atenção básica, necessitando de intervenções nos níveis secundário e terciário. O SUS não se limita à assistência, pois também atua na saúde através das vigilâncias sanitária, epidemiológica e alimentar, na formulação e execução da política de hemoderivados, na regulação da prestação dos serviços privados conveniados e na formulação da política de formação para a área da saúde.

Como esclarecem Vasconcelos e Pasche (2006), o SUS é o arranjo organizacional do Estado brasileiro que dá suporte à efetivação da política de saúde no país. Seu objetivo é coordenar e integrar as ações de saúde nas três esferas de governo, para atender de maneira funcional às demandas por atenção à saúde. A resposta efetiva aos problemas de saúde é dependente da gestão municipal e de sua articulação com os níveis estadual e federal. No entanto, a racionalidade para a operação do sistema é dependente de outros atores envolvidos.

O DSC5 "inserir o PSF que faz o reconhecimento da área em que atua, encaixando-se no contexto de vida das pessoas, conseguindo trabalhar direto na realidade" mostra uma visão atualizada dos alunos do processo de reorganização da atenção básica que está se processando em todo o território nacional. Possivelmente este interesse pela Estratégia de Saúde da Família esteja atrelado às perspectivas do mercado de trabalho, com a inclusão do dentista na equipe de saúde bucal, já que este se constitui no espaço mais promissor de inserção do profissional na rede pública na atualidade. No entanto, não se pode negar que a ESF tem sido a forma com que o setor público vem processando, na maioria das unidades de saúde, a atenção à saúde à população, através da participação das equipes de saúde da família no reconhecimento do território onde vivem os usuários da unidade de saúde, podendo agir dentro da realidade de vida das pessoas, o que facilita muito o trabalho a ser desenvolvido. Esta proposta leva em consideração 
não apenas os aspectos técnicos de cada uma das profissóes envolvidas, mas procura também a humanização do atendimento, pelo acolhimento por meio da escuta qualificada, levando em consideração as razões da procura do usuário à unidade de saúde e finalizando com seu devido encaminhamento.

De acordo com Silva (2008), a ESF tem duas incumbências: ter que resolver os problemas de saúde apresentados pela população e interferir diretamente nos fatores determinantes do processo saúde-doença. Para tal, deverá conhecer como está estruturada a população em seu território de ação, sendo que esse conhecimento deverá abranger as condições e estilos de vida desta população, além dos fatores biológicos que a permeiam e da organização da atenção básica de forma resolutiva.

\section{4o. tema: $\mathrm{O}$ compromisso do dentista com a ética profissional}

O DSC7 foi inserido na IC seguinte, "necessidade de manter o compromisso profissional", com o seguinte teor:

A Odontologia não está muito ligada no âmbito social, bem pelo contrário, os profissionais estão mais pensando no lado financeiro. No serviço público precisa haver mais comprometimento da maioria dos dentistas, uma vez que pensam no seu trabalho mais como um bico, não se empenhando muito. $O$ que se vê são profissionais trabalhando a metade do tempo de contrato e não mostrando excelência no que estão fazendo porque acham que ganham muito pouco.

Verifica-se inicialmente que os alunos entendem que a maior preocupação dos dentistas é desenvolver seu trabalho onde consigam melhores ganhos financeiros, e isto pode ser justificado pela escolha da maioria dos profissionais em se instalarem na rede privada, local onde podem atender ao seguimento da população que tem maior poder aquisitivo e que pode arcar com os custos do tratamento odontológico. Por outro lado, declaram que os dentistas do setor público, de maneira geral, não têm compromisso com as responsabilidades inerentes ao seu emprego, por considerá-lo apenas uma complementação de sua remuneração e por ganharem pouco, passando então a não cumprir a jornada de trabalho.

As observações relatadas são em parte verdadeiras, causadas pela conduta de certos dentistas do serviço público de saúde; no entanto, esta visão não pode ser generalizada, uma vez que muitos municípios brasileiros já apresentam experiências exitosas de boa prestação de serviços de saúde, em decorrência da dedicação dos seus profissionais. $\mathrm{O}$ crescimento da oferta de trabalho na rede pública, seja por 
processo seletivo ou concurso, tem levado os dentistas admitidos a se identificarem com seu emprego e o valorizarem. Todavia, independentemente do setor onde o profissional trabalhe, seu desempenho deve estar dirigido ao princípio de justiça, promovendo o cuidado e a proteção às pessoas com o máximo de respeito possível.

A assistência odontológica não pode considerar as pessoas como objeto de sua prática, mas como sujeitos que apresentam dor e sofrimento, que têm expectativas quanto à resolução de seus problemas de saúde. Deve vir permeada do respeito, considerando os valores, os direitos e a realidade socioeconômica da pessoa atendida, assim como dentro da maior qualidade técnica possível, levando em consideração o tempo necessário para o procedimento, com o uso de materiais atualizados e adequados e respeitando as normas de biossegurança. A prática profissional precisa ser consciente e crítica, permitindo que a pessoa tratada restabeleça seu quadro de saúde. Para que isto ocorra, os gestores públicos devem criar mecanismos para a capacitação dos dentistas contratados, especialmente no que diz respeito ao conhecimento do SUS, das Políticas Nacionais de Saúde Bucal e Promoção da Saúde e da Estratégia de Saúde da Família.

A consolidação do SUS vem determinando novas exigências, tanto na estrutura dos serviços de saúde como em sua forma de promover a assistência. Isto tem criado a necessidade de profissionais preparados para enfrentar as exigências desse novo modelo de atenção à saúde. Um dos principais obstáculos é o trabalho de profissionais desvinculados da realidade social, fruto de sua formação. Este fato fica evidente, na Odontologia, com um ensino praticamente baseado em procedimentos de média e alta densidade tecnológica, formando profissionais altamente especializados e despreparados para as ações de saúde pública (SILVA; ROSA, 1996).

Para Prado e Garrafa (2006), o profissional de saúde, além do domínio de conhecimento científico e técnico, deve ter a capacidade de análise, de reflexão e de posicionamento das condições de saúde e de vida das pessoas assistidas. A prática odontológica, para ser capaz de provocar mudanças favoráveis à saúde da população, precisa se processar de forma equilibrada, equânime e justa. Isto pressupõe que a mesma esteja orientada à educação, à promoção da saúde e à reabilitação. 


\section{Considerações finais}

O conteúdo dos discursos dos alunos evidencia a necessidade de os sete cursos de Odontologia participantes desta pesquisa promoverem, com seu corpo docente, uma reflexão crítica entre a forma como se processa a apreensão dos conteúdos ministrados e da prática executada, pois tal compreensão conduz o modo como esses alunos procedem no seu exercício profissional.

A conscientização das pessoas quanto aos problemas de saúde e a tomada de decisão para mudança de comportamento visando à aquisição de hábitos mais saudáveis não podem ser garantidas apenas pela difusão de conhecimento realizada pelo dentista. O empoderamento do indivíduo e da comunidade e o desenvolvimento de habilidades pessoais para o autocuidado em saúde precisam transcender o acesso à educação. Por isso, o papel do dentista deve ser o de sujeito de mudança, promovendo uma educação capaz de produzir sujeitos autônomos e reflexivos, com capacidade de analisar sua situação de vida e de tomar as decisões que considerarem mais apropriadas.

É inegável que as necessidades de saúde precisam ser solucionadas, mas o restabelecimento do quadro de saúde bucal será insuficiente para promover a inclusão social se os demais problemas da população não forem atendidos. As soluções não se encontram apenas no setor saúde, pois no trabalho em saúde, os determinantes sociais, econômicos, políticos e culturais do processo saúde-doença precisam ser levados em consideração, e estes dependem de articulações entre as múltiplas instituições públicas no estabelecimento conjunto de políticas sociais mais abrangentes e resolutivas.

O SUS não pode ser visto apenas como prestação de assistência à população, uma vez que sua atuação é mais abrangente com ações das vigilâncias sanitária, epidemiológica e alimentar, na formulação e execução da política de hemoderivados, na regulação da prestação dos serviços privados conveniados e na formulação da política de formação para a área da saúde.

A saúde bucal não pode ser mero objeto de consumo, devendo estar pautada na ética, constituindo instrumento de construção da cidadania e de libertação. O dentista deve atuar como o responsável no apoio a essas conquistas, assumindo seu compromisso social de intervir para melhorar a qualidade de vida das pessoas, exercendo seu papel de cidadão. 


\section{Referências}

BRASIL. Ministério da Saúde. Conselho Nacional de Saúde. 3. ${ }^{a}$ Conferência Nacional de Saúde Bucal: acesso e qualidade superando a exclusão social. Brasília: Ministério da Saúde, 2005.

CONSELHO FEDERAL DE ODONTOLOGIA. Resolução CFO 42/2003. Código de Ética Odontológica. Disponível em: www.crosc.org.br/codigo_etica.pdf Acesso em: 25 fev 2008.

FAVARÃO, Neide. R. L.; ARAÚJO, Cíntia. S. A. importância da interdisciplinaridade no ensino superior. EDUCERE - Revista da Educação, v. 4, n. 2, p. 103-115, jul.-dez. 2004.

FONTANELLA, B. J. B.; RICAS, J.; TURATO, E. R. Amostragem por saturação em pesquisas qualitativas em saúde: contribuições teóricas. Cadernos de Saúde Pública, v. 24, n. 1, p. 17-27, jan. 2008.

FREITAS, Cláudia H. S. de M. Dilemas no exercício profissional da Odontologia: a autonomia em questão. Interface: Comunic, Saúde, Educ., v. 11, n. 21, p. 25-38, jan.-abr. 2007.

LEFÈVRE, Fernando; LEFÈVRE, Ana M. C. O discurso do sujeito coletivo: um novo enfoque em pesquisa qualitativa (desdobramentos). Caxias do Sul: Educs, 2003.

LUIZ, Olinda do C. Direitos e equidade: princípios éticos para a saúde. Arq. Med. ABC., v. 30, n. 2, p. 69-75, 2005.

MOYSÉS, Simone T.; WATT, Richard. Promoção de saúde bucal: definiçōes. In: BUISCHI, Ivone de P. (org.). Promoção de saúde bucal na clínica odontológica. São Paulo: Artes Médicas, 2000.

NARVAI, Paulo C. Odontologia e saúde bucal coletiva. São Paulo: Hucitec, 1994.

NICKEL, Daniela A.; CORRALES, Mariana. O mercado de trabalho em tempos de flexibilização: análise das vinculações contratuais dos profissionais de nível superior do Programa Saúde da Família em Santa Catarina. 2006. 34 f. Monografia (Especialização em Saúde Pública) - Programa de PósGraduação em Saúde Pública, Universidade Federal de Santa Catarina, Florianópolis, 2006.

NICOLIELO, Juliana; BASTOS, José R. de M. Satisfação profissional do cirurgiāo-dentista conforme tempo de formado. Revista Faculdade de Odontologia de Bauru, v. 10, n. 2, p. 69-74, 2002.

OPAS. Desigualdades em salud. Boletim Epidemiológico. v. 25, n. 4, dez. 2004.

PRADO, Mauro M. do; GARRAFA, Volnei. A Bioética na formação em Odontologia: importância para uma prática consciente e crítica. Comunicação Ciência e Saúde, v. 17, n. 4, p. 263-74, 2006.

REIBNITZ, Kenya. S.; PRADO, Marta. L. do. Criatividade e relação pedagógica: em busca de caminhos para a formação do profissional crítico criativo. Brasília. Revista Brasileira de Enfermagem, v. 4, n. 56, p. 439-442, jul.-ago. 2003.

REIBNITZ JUNIOR, Calvino. A saúde bucal no paradigma da promoção da saúde: o campo conceitual de alunos dos cursos de Odontologia de Santa Catarina. Dissertação (Mestrado em Saúde Pública) Universidade Federal de Santa Catarina, Florianópolis, 2008. 
SILVA, Antônio D. S. Processo de trabalho das equipes multiprofissionais sob a lógica da Estratégia de Saúde da Família: o uso de ferramentas de saúde da família na construção do cuidado em saúde. In: MOYSÉS, Simone T.; KRIGER, Léo; MOYSÉS, Samuel J. Saúde bucal das famílias: trabalhando com evidências. São Paulo: Artes Médicas, 2008. p. 65-80

SILVA, Silvio R. C. da; ROSA, Antônio G. F. Características dos cirurgiōes-dentistas com vínculo empregatício em empresas públicas e/ou privadas no município de Araraquara - SP. Revista de Odontologia UNESP, v. 25, n. esp., p. 9-18, 1996.

SEGRE, Marco; FERRAZ, Flávio C. O conceito de saúde. Revista de Saúde Pública, v. 31, n. 5, p. 538-42, dez. 1997.

SOUZA, Gislaine A. de; SILVA, Ângela M. M. da; GALVÃO, Rogério. A auto-eficácia como mediadora da melhora em índices clínicos de saúde oral. Pesquisa Odontológica Brasileira, v. 16, n. 1, p. 57-62, jan.-mar. 2002.

VASCONCELOS, Cipriano M. de; PASCHE, Dário F. O Sistema Único de Saúde. In: CAMPOS, G. W. et al. (orgs.). Tratado de Saúde Coletiva. Rio de Janeiro: Fiocruz, 2006. p. 531-562.

\section{Nota}

${ }^{1}$ Pesquisa derivada da dissertação $A$ saúde bucal no paradigma da promoção da saúde: o campo conceitual de alunos dos cursos de Odontologia de Santa Catarina (REIBNITZ JÚNIOR, 2008), orientada por João Carlos Caetano e coorientada por Marta Lenise do Prado. 
Contribution of dental care in the resolution ofpeople's health problems: the viewpoint of Dentistry students

The aim of this study was to analyze and discuss the comprehension of Dentistry students from seven Dentistry Schools in Santa Catarina State, regarding the contribution of dental care in the resolution of people's health problems. The methodological approach was a qualitative research based on the Coletive Subject Discourse Technique (CSD), applied to 35 interviews. Based on the results, seven CSD's were developed. The students' viewpoints showed that: the contribution of dental care comprises the dissemination of oral health from the dentist to the population as a way for prevention; clinical dental care requires proper technical skills of the dentist, involving proper materials, instruments, and equipments associated to attendance of ethical concepts and satisfaction with the accomplished task; the resolution of dental problems is a way to promote people's self-esteem, resulting in social inclusion; Dentistry is not limited to specific questions, and issues from other professions should be considered; and finally, there is a need to improve the infrastructure and access to public health services. In addition, the results suggest the need of carrying out discussions among dental students and academic staff, in order to produce critical reflections on the conceptual field of oral health.

> Key words: Oral health; health promotion; health policy; higher education. 